Original article

\title{
Hemato-biochemical responses of rats co-exposed to heat stress and trichloroethylene vapors
}

\author{
Zahra Zamanian ${ }^{1}$, Saeed Yousefinejad ${ }^{1}$, Somayeh Farhang Dehghan ${ }^{2}$, Abdolrasoul Rahmani ${ }^{3}$ \\ ${ }^{1}$ Shiraz University of Medical Sciences, Shiraz, Iran \\ 2 Shahid Beheshti University of Medical Sciences, Tehran, Iran \\ ${ }^{3}$ Larestan University of Medical Sciences, Larestan, Iran
}

Received 4 November 2020, Revised 11 April 2021, Accepted 27 October 2021

(C) 2020, Russian Open Medical Journal

Abstract: Aim - The present study was aimed to measure some hemato-biochemical parameters of male Sprague-Dawley rats co-exposed to different levels of heat stress and Trichloroethylene (TCE) exposure.

Methods - All male rats were randomly divided into nine equal groups of 5 animals each. They were exposed to heat stress and TCE vapors in a subacute manner $(8 \mathrm{hr} /$ day for 10 days) according to experimental design. Blood samples were taken from the heart of all animals at the end of the 10th day of exposure. Hematology and biochemical parameters were determined using the automated hematology analyzer and an automated biochemistry, respectively.

Results - The values of WBC, RBC and HB significantly decreased after co-exposure $250 \mathrm{ppm}$ TCE and extreme heat stress; although, this exposure condition lead to statistically significant increase in mean levels of MCV, RDW, ALP, CPK and LDH. Our findings indicated that there were the subtractive and independent interactions for the hematological parameters and the additive, subtractive and independent interactions for biochemical parameters based on the exposure level to trichloroethylene and heat stress.

Conclusion - Heat stress may increase sensitivity of workers to trichloroethylene and the simultaneous effects of exposure provide the circumstances for the occurrence of a variety of disorders.

Keywords: Hematology parameter, Biochemical parameter, Trichloroethylene, Heat Stress, Sub-acute exposure.

Cite as Zamanian Z, Yousefinejad S, Dehghan SF, Rahmani A. Hemato-biochemical responses of rats co-exposed to heat stress and trichloroethylene vapors. Russian Open Medical Journal 2021; 10: e0405.

Correspondence to Mian Abdolrasoul Rahmani. Address: Larestan University of Medical Sciences, Imam Khomeini Square, at the beginning of Saadi Boulevard, Larestan, 74318-95639, Fars, Iran. Phone: +980712247110. Email: rahmaniabdolrasoul218@gmail.com.

\section{Introduction}

Trichloroethylene (TCE) is one of the bestknown solvents for industrial cleaning and degreasing operations and it has been estimated that more than 3.5 million individuals are exposed to trichloroethylene annually [1]. Previous studies have found that trichloroethylene adversely effects the immune system, liver, kidney, and some hematological parameters [1]. Ramdhan et al. (2010) also reported that exposure to trichloroethylene can lead to the increased plasma activity of alanine aminotransferase (ALT) and aspartate aminotransferase (AST) in all mouse lines [2]. It is well recognized that some hematobiochemical parameters can be affected by heat stress [3]. In this regard, Srikandakumar et al. (2003) reported creatinine phosphokinase (CPK) and AST have been decreased in sheep subjected to the heat stress which adicted the observations of Gattani et al. (2016) who reported the increased mean values of AST and ALT as well as increase of hemoglobin $(\mathrm{Hb})$ concentration, red blood cells (RBCs), and packed cell volume (PCV) in adult turkeys during summer season under arid tropical environment [4, 5]. According to Norloei et al. (2017), a positive relationship was found between the variations of some hematological parameters and Wet Bulb Globe Temperature (WBGT) index among workers engaged in a foundry and metal melting plant [6].
Over a century, it has been recognized that the physiological responses due to heat stress can be intensified by environmental toxicant exposure [7]. The physiological responses to chemical exposure, heat stress or the combination of the two stressors can be a change in absorption, distribution, metabolism and excretion processes of toxicants caused by altering core body temperature [7]. Reduction in core temperature (i.e., hypothermia) due to the thermoregulatory response to heat stress and many chemicals may be related to the delayed clearance of most toxicants from the body [7]. Under heat stress, several physiological mechanisms like increases in sweat rate and skin blood flow are activated which can result in greater uptake of chemical compounds [8].

There are a variety of workplace environments such as foundry and metal forming industries, paint and resin industries and brake pad manufacturers, predisposing workers to the combination of heat and trichloroethylene exposure; provided that literature is so incomplete with respect to variability of hematology and biochemical parameters in response with different exposure levels to heat stress and trichloroethylene vapors. The present study was aimed to measure some hemato-biochemical responses of male Sprague-Dawley rats co-exposed to different levels of heat and trichloroethylene, under controlled laboratory conditions. The results from this study can potentially help in furtherance of 
research in a particular field of knowledge and can be a guidance in administering the workplace health promotion program for this kind of exposures.

\section{Material and Methods}

\section{Animals}

Male Sprague-Dawley rats between 250 and 300 $\mathrm{g}$ body weight and male rats at $10-12 \mathrm{wk}$. of age were purchased from Animal House of Shiraz University of Medical Sciences and served as blood donors. They had been fed with normal rat diet (Rodent Cubes, Allied Cooperative Feed and Livestock Services, Larestan) and drank tap water ad lib. Animals were housed in a controlled environment with a $12 \mathrm{~h}$ light/dark cycle (light on at 7 a.m. and light off at 7 p.m.), constant air temperature $\left(23 \pm 1^{\circ} \mathrm{C}\right)$ and relative humidity $(35-40 \%)$.

\section{Exposure chamber}

A rectangular chamber sized $35 \times 40 \times 70 \mathrm{~cm}$ was designed to measure the effects of co-exposure to heat stress and trichloroethylene vapors on the rats (Figure 1). The chamber had a stainless steel (8-mil) frame covered with insulating glass or acrylic double glazing made up of 2 panes of glass separated by a vacuum. A Hi-Tec HI-AH26 (Canada) cool and warm mist humidifier was provided for controlling temperature and humidity. Wet
Bulb Globe Temperature (WBGT) as a more accurate index to assess heat stress was measured using two WBGT heat stress meters (Sper Scientific, Model 800036; China) [9]. Air temperature and relative humidity were measured by a digital thermometer and hygrometer (Super Digital Timer, DTB-8MA; Iran). X-fans (RDM4010S1 $40 \times 40 \times 10 \mathrm{~mm}$ ) were installed throughout the chamber for regulating airflow of trichloroethylene vapor, controlling temperature, compensating for pressure drops and making uniform air flow distribution.

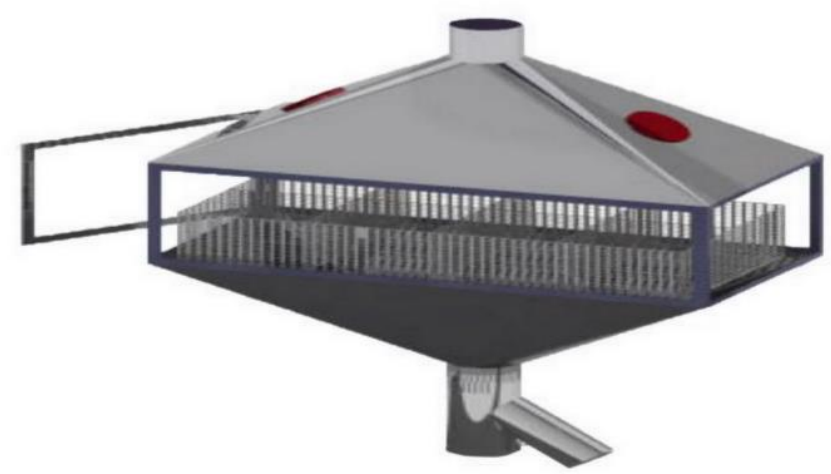

Figure 1. Exposure chamber.

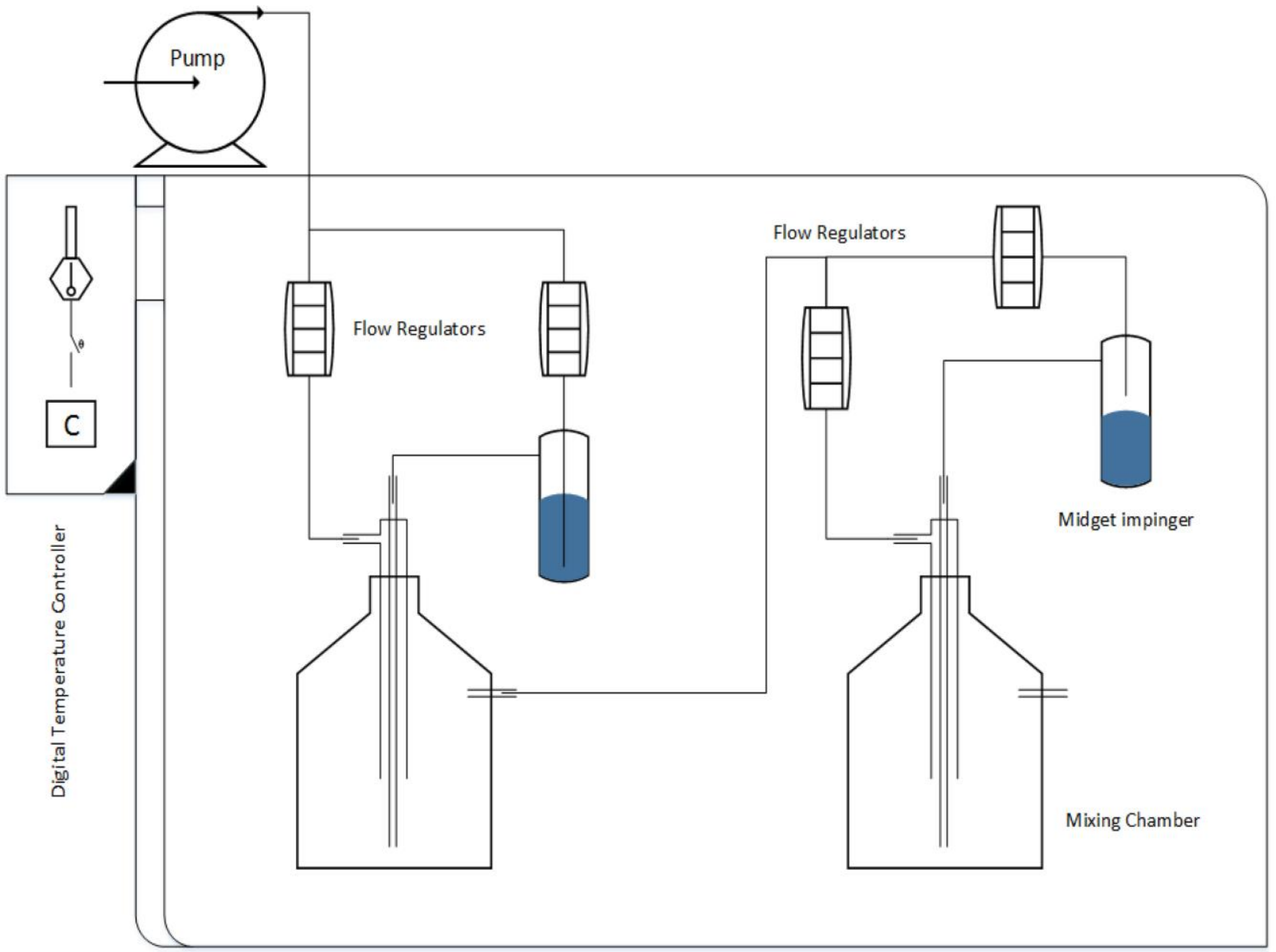

Figure 2. Generation of specific concentration of trichloroethylene vapor using the evaporation method. 
Table1. Experimental design of the study

\begin{tabular}{lcc}
\hline Group & Trichloroethylene $(\mathrm{ppm})$ & WBGT $\left({ }^{\circ} \mathrm{C}\right)$ \\
\hline 1 (Control) & 0 & $23 \pm 1$ \\
2 & 100 & $23 \pm 1$ \\
3 & 250 & $23 \pm 1$ \\
4 & 0 & $29 \pm 1$ \\
5 & 0 & $33 \pm 1$ \\
6 & 100 & $29 \pm 1$ \\
7 & 100 & $33 \pm 1$ \\
8 & 250 & $29 \pm 1$ \\
9 & 250 & $33 \pm 1$ \\
\hline
\end{tabular}

Table 2. Interactions between trichloroethylene and thermal stress

\begin{tabular}{lc}
\hline Type of interaction & Numerical example \\
\hline Independent interactions* & $2+4=4$ \\
Subtractive or divisive interactions (antagonism) & $0+3=1$ \\
& $2+4=3$ \\
& $-4+4=0$ \\
Additive interactions & $2+4=6$ \\
Potentiation** & $0+3=9$ \\
Multiplicative interactions (synergism) & $2+4=25$ \\
\hline
\end{tabular}

* The interaction is equal to the largest single effect; ** The number 0 indicates absorption, but no toxic effect.

\section{Production of fixed concentration of TCE vapors}

Trichloroethylene (purity 99\%) was provided by the Japan Association for Hygiene of Chlorinated Solvents. In order to achieve specific concentrations of trichloroethylene vapors, dynamic generation system based on evaporation method was used [10]. The technique is based on passing a pure diluting gas close to the surface and inside the liquid trichloroethylene (air was blown in a $250 \mathrm{ml}$ midget impinger). In the literature, it is suggested that the flow rate of the diluting gas should be sufficient low in order to ensure that the gas concentration reaches the state of saturation [11]. A system of flow regulators is ordinarily used to measure the flow rate. A schematic diagram of the apparatus for the generation of fixed concentration of trichloroethylene vapors by an evaporation method is shown in Figure 2.

\section{Experimental Protocol}

The design of the experiment is shown in Table 1. The animals were acclimatized for 10 days prior to the experiment. Then, all the male rats were randomly divided into nine equal groups of 5 animals each. They were exposed to heat stress and TCE vapors in a subacute manner ( $8 \mathrm{hr} /$ day for 10 days) according to experimental design.

\section{Inhalation exposure to trichloroethylene}

Exposure by inhalation was selected as a main route of chemical absorption at workplaces in comparison with the ingestion and dermal route. The target concentrations of trichloroethylene were set at $100 \mathrm{ppm}$ based on Permissible Exposure Limits of Occupational Safety and Health Administration, and at $250 \mathrm{ppm}$ as an induction of the severe halation exposure [12]. Trichloroethylene concentrations in the chamber were measured every 15 min by gas chromatography (SCION 456-GC; United Kingdom) and controlled to within $\pm 1 \%$ of the target concentration.

\section{Exposure to heat stress}

The values of WBGT (heat stress index) were set at $23 \pm 1^{\circ} \mathrm{C}$ as heat comfort range, $29 \pm 1^{\circ} \mathrm{C}$ based on OSHA guideline for moderate work load with $75 \%$ work- $25 \%$ rest regimen, and $33 \pm 1^{\circ} \mathrm{C}$ as an induction of extreme heat stress [12]. The different groups of rats were subjected to the stressor from 8:00 to 16:00 according experimental protocol. During the experiments, air temperature and relative humidity can be lowered or raised within the range of $25-40{ }^{\circ} \mathrm{C}$ and $40-60 \%$, respectively.

\section{Simultaneous exposure to trichloroethylene and heat stress}

As can be seen in Table 1, four groups (No. 6, 7, 8 and 9) experienced the simultaneous exposure to trichloroethylene and heat stress. There was the heat comfort condition for the Groups 1, 2 and 3. Type of interactions between trichloroethylene and heat stress can be expressed mathematically according to Table 2 [13].

\section{Determination of hemato-biochemical parameters}

Blood samples were taken from the heart of all animals at the end of the 10th day of exposure. HB, RBC, WBC, HCT, MCV and PLT were determined using the automated hematology analyzer (Nihon Kohden Celltac alpha MEK-6400, Japan). The remaining blood was transferred to polypropylene microtest tubes and centrifuged for $10 \mathrm{~min}$ at 3,000 revolutions per minute for separating the serum. The AST, ALT, BT and BD, ALP, LDH and CPK were measured by using an automated biochemistry analyzer (Roche Diagnostics, Cobas Mira; United States) according to the manufacturer's protocol.

\section{Statistical Analysis}

Statistical data analysis was performed with SPSS Version 22.0 software. Data was presented as means with the standard deviation (SD). The Independent t-test and analysis of variance (ANOVA) was applied to compare the means of hematobiochemical parameters between the different studied groups. A bivariate correlation will be conducted to assess the relationship between TCE and heat stress exposure and values of the studied parameters. Evaluations for interactions were statistically calculated by the method previously described by Winder \& Stacy (2004), based on an ANOVA test [14]. Statistical interaction is present on the independent scale when the sum of the effects of the individual factors is similar to the single effects of the factors. In the subtractive or divisive interactions (antagonism), the effect of co-exposure is actually less than the sum of the effect of the two factors taken independently of each other. In the interaction on an additive scale, the effect of two factor is equal to the sum of the effect of the factors taken separately. When interaction between two agents resulting in a toxic response significantly greater than the sum of individual responses to each and control group, the interaction called potentiation; but with the proviso that one of the factors should not have a significant difference with the control group. Where the effects multiply, the interaction is called synergism and the effect may be many more times than can be predicted by the individual effects and control group. The level of significance at 0.05 was considered to be statistically significant. 
Table 3. Hemato-biochemical responses to interaction of trichloroethylene (concentration 100 ppm) and heat stress $\left(\right.$ WBGT=29 $\left.\pm 1^{\circ} \mathrm{C}\right)$

\begin{tabular}{|c|c|c|c|c|c|}
\hline \multirow{2}{*}{$\begin{array}{l}\text { Hemato-Biochemical } \\
\text { Parameters }\end{array}$} & \multirow{2}{*}{$\begin{array}{c}\text { Control group }(\mathrm{N}=5) \\
0 \mathrm{ppm} / 23 \pm 1^{\circ} \mathrm{C}\end{array}$} & \multicolumn{4}{|c|}{ Exposed group $(N=5)$} \\
\hline & & 100 ppm & $29 \pm 1^{\circ} \mathrm{C}$ & $100 \mathrm{ppm} / 29 \pm 1^{\circ} \mathrm{C}$ & Interaction \\
\hline WBC $\left(10^{3} / \mu \mathrm{l}\right)$ & $8.94 \pm 1.29$ & $11.52 \pm 1.55^{*}$ & $6.00 \pm 1.01^{*}$ & $6.98 \pm 1.25^{*}$ & Subtractive \\
\hline $\operatorname{RBC}\left(10^{6} / \mu \mathrm{l}\right)$ & $8.99 \pm 0.20$ & $8.33 \pm 0.39 *$ & $8.51 \pm 0.17 *$ & $8.04 \pm 0.41 *$ & Subtractive \\
\hline $\mathrm{HB}(\mathrm{g} / \mathrm{dl})$ & $16.04 \pm 0.40$ & $14.66 \pm 1.11 *$ & $15.16 \pm 0.41^{*}$ & $15.86 \pm 0.58$ & Independent \\
\hline HCT (\%) & $46.92 \pm 1.03$ & $43.50 \pm 2.98 *$ & $44.32 \pm 1.55^{*}$ & $44.92 \pm 1.46$ & Independent \\
\hline $\operatorname{MCV}(f \mathrm{l})$ & $52.20 \pm 1.09$ & $52.20 \pm 2.04$ & $52 \pm 1.58$ & $56 \pm 1.22 *$ & Independent \\
\hline $\operatorname{PLT}\left(10^{3} / \mu \mathrm{l}\right)$ & $727.20 \pm 45.10$ & $841.20 \pm 50 *$ & $668.40 \pm 41.60$ & $564.2 \pm 41.70^{*}$ & Subtractive \\
\hline RDW (\%) & $14.72 \pm 0.45$ & $15.06 \pm 1.25$ & $14.9 \pm 1.01$ & $14.98 \pm 1.05$ & Independent \\
\hline AST (IU/I) & $211.20 \pm 33.10$ & $207.60 \pm 50.10$ & $262.60 \pm 51.50$ & $249.20 \pm 42.50$ & Independent \\
\hline ALT (IU/I) & $44.80 \pm 5.06$ & $76.60 \pm 6.04 *$ & $71.00 \pm 7.59^{*}$ & $77.2 \pm 5.88^{*}$ & Independent \\
\hline ALP (IU/I) & $206.60 \pm 13.95$ & $558.00 \pm 23.16^{*}$ & $298.00 \pm 32.86 *$ & $744.2 \pm 38.00 *$ & Additive \\
\hline BT (mg/dl) & $0.90 \pm 0.14$ & $0.86 \pm 0.16$ & $0.91 \pm 0.19$ & $0.92 \pm 0.16$ & Independent \\
\hline $\mathrm{BD}(\mathrm{mg} / \mathrm{dl})$ & $0.25 \pm 0.09$ & $0.24 \pm 0.09$ & $0.22 \pm 0.03$ & $0.29 \pm 0.05$ & Independent \\
\hline CPK (IU/I) & $1258 \pm 76.22$ & $2019.40 \pm 84.2^{*}$ & $1690 \pm 65.7^{*}$ & $4011.20 \pm 97.70 *$ & Additive \\
\hline $\mathrm{LDH}(\mathrm{IU} / \mathrm{I})$ & $2735.8 \pm 88.32$ & $2626.20 \pm 79.90$ & $4076 \pm 81.10^{*}$ & $3540 \pm 74.60 *$ & Subtractive \\
\hline
\end{tabular}

* Mean difference of variable between control and case group is statistically significant. WBC, White blood cell; RBC, Red blood cell; HB, Hemoglobin; HCT, Hematocrit; MCV, Mean corpuscular volume; PLT, Platelet count; RDW, Red cell distribution width; AST, Aspartate aminotransferase; ALT, Alanine aminotransferase; ALP, Alkaline phosphatase; BT, Bilirubin total; BD, Bilirubin direct; CPK, Creatinine phosphokinase; LDH, Lactate dehydrogenase.

Table 4. Hemato-biochemical responses to interaction of trichloroethylene (concentration 100 ppm) and heat stress $\left(W B G T=33 \pm 1^{\circ} \mathrm{C}\right.$ )

\begin{tabular}{|c|c|c|c|c|c|}
\hline \multirow{2}{*}{$\begin{array}{l}\text { Hemato-Biochemical } \\
\text { Parameters }\end{array}$} & \multirow{2}{*}{ 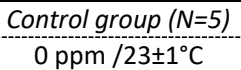 } & \multicolumn{4}{|c|}{ Exposed group $(N=5)$} \\
\hline & & 100 ppm & $33 \pm 1^{\circ} \mathrm{C}$ & $100 \mathrm{ppm} / 33 \pm 1^{\circ} \mathrm{C}$ & Interaction \\
\hline WBC $\left(10^{3} / \mu \mathrm{l}\right)$ & $8.94 \pm 1.29$ & $11.52 \pm 1.55^{*}$ & $5.98 \pm 1.63^{*}$ & $4.76 \pm 1.82 *$ & Subtractive \\
\hline $\operatorname{RBC}\left(10^{6} / \mu \mathrm{l}\right)$ & $8.99 \pm 0.20$ & $8.33 \pm 0.39 *$ & $9.04 \pm 0.48$ & $7.82 \pm 0.82 *$ & Subtractive \\
\hline $\mathrm{HB}(\mathrm{g} / \mathrm{dl})$ & $16.04 \pm 0.40$ & $14.66 \pm 1.11^{*}$ & $17 \pm 0.49 *$ & $14.24 \pm 0.48 *$ & Subtractive \\
\hline НCT (\%) & $46.92 \pm 1.03$ & $43.5 \pm 2.98 *$ & $51.66 \pm 1.15^{*}$ & $40.67 \pm 1.15^{*}$ & Subtractive \\
\hline $\operatorname{MCV}(f l)$ & $52.20 \pm 1.09$ & $52.20 \pm 2.04$ & $57.00 \pm 2.00 *$ & $54.20 \pm 2.96$ & Subtractive \\
\hline $\operatorname{PLT}\left(10^{3} / \mu \mathrm{l}\right)$ & $727.20 \pm 45.10$ & $841.20 \pm 50^{*}$ & $669.60 \pm 46.20$ & $549 \pm 49.20 *$ & Subtractive \\
\hline RDW (\%) & $14.72 \pm 0.45$ & $15.06 \pm 1.25$ & $14.86 \pm 1.04$ & $16.76 \pm 1.84 *$ & Independent \\
\hline AST (IU/I) & $211.20 \pm 33.10$ & $207.60 \pm 50.10$ & $326.20 \pm 69.90^{*}$ & $209.20 \pm 4.20$ & Subtractive \\
\hline ALT (IU/I) & $44.80 \pm 5.06$ & $76.6 \pm 6.04^{*}$ & $77.20 \pm 8.09 *$ & $86.80 \pm 5.09 *$ & Independent \\
\hline ALP (IU/I) & $206.60 \pm 13.95$ & $558.0 \pm 23.16^{*}$ & $321.80 \pm 18.58 *$ & $630.20 \pm 19.65^{*}$ & Additive \\
\hline BT (mg/dl) & $0.90 \pm 0.14$ & $0.86 \pm 0.16$ & $1.01 \pm 0.22$ & $0.80 \pm 0.00$ & Subtractive \\
\hline $\mathrm{BD}(\mathrm{mg} / \mathrm{dl})$ & $0.25 \pm 0.09$ & $0.24 \pm 0.09$ & $0.28 \pm 0.10$ & $0.26 \pm 0.05$ & Independent \\
\hline CPK (IU/I) & $1258 \pm 76.22$ & $2019.40 \pm 84.2^{*}$ & $3300 \pm 80.82 *$ & $2912.40 \pm 75.83^{*}$ & Subtractive \\
\hline LDH (IU/I) & $2735.80 \pm 88.32$ & $2626.20 \pm 79.90$ & $3752 \pm 82.89 *$ & $4390 \pm 80.45^{*}$ & Additive \\
\hline
\end{tabular}

* Mean difference of variable between control and case group is statistically significant. WBC, White blood cell; RBC, Red blood cell; HB, Hemoglobin; HCT, Hematocrit; MCV, Mean corpuscular volume; PLT, Platelet count; RDW, Red cell distribution width; AST, Aspartate aminotransferase; ALT, Alanine aminotransferase; ALP, Alkaline phosphatase; BT, Bilirubin total; BD, Bilirubin direct; CPK, Creatinine phosphokinase; LDH, Lactate dehydrogenase.

Table 5. Hemato-biochemical responses to interaction of trichloroethylene (concentration 250 ppm) and heat stress (WBGT=29 $\pm 1^{\circ} \mathrm{C}$ )

\begin{tabular}{|c|c|c|c|c|c|}
\hline \multirow{2}{*}{$\begin{array}{l}\text { Hemato-Biochemical } \\
\text { Parameters }\end{array}$} & \multirow{2}{*}{$\begin{array}{c}\text { Control group }(\mathrm{N}=5) \\
0 \mathrm{ppm} / 23 \pm 1^{\circ} \mathrm{C}\end{array}$} & \multicolumn{4}{|c|}{ Exposed group $(N=5)$} \\
\hline & & $250 \mathrm{ppm}$ & $29 \pm 1^{\circ} \mathrm{C}$ & $250 \mathrm{ppm} / 29 \pm 1^{\circ} \mathrm{C}$ & Interaction \\
\hline WBC $\left(10^{3} / \mu \mathrm{l}\right)$ & $8.94 \pm 1.29$ & $13.10 \pm 1.11^{*}$ & $6.00 \pm 1.01 *$ & $6.60 \pm 1.20 *$ & Subtractive \\
\hline $\mathrm{RBC}\left(10^{6} / \mu \mathrm{l}\right)$ & $8.99 \pm 0.20$ & $8.29 \pm 0.38 *$ & $8.51 \pm 0.17^{*}$ & $8.24 \pm 0.35^{*}$ & Independent \\
\hline $\mathrm{HB}(\mathrm{g} / \mathrm{dl})$ & $16.04 \pm 0.40$ & $15.38 \pm 0.46^{*}$ & $15.16 \pm 0.41^{*}$ & $15.44 \pm 0.45$ & Independent \\
\hline HCT (\%) & $46.92 \pm 1.03$ & $43.76 \pm 1.73^{*}$ & $44.32 \pm 1.55^{*}$ & $46.10 \pm 1.05$ & Independent \\
\hline $\operatorname{MCV}(f l)$ & $52.20 \pm 1.09$ & $52.80 \pm 0.83$ & $52.00 \pm 1.58$ & $54.80 \pm 1.92 *$ & Independent \\
\hline $\operatorname{PLT}\left(10^{3} / \mu \mathrm{l}\right)$ & $727.20 \pm 45.10$ & $596.60 \pm 49.90 *$ & $668.40 \pm 41.60$ & $659.60 \pm 44.30 *$ & Independent \\
\hline RDW (\%) & $14.72 \pm 0.45$ & $14.66 \pm 0.76$ & $14.9 \pm 1.01$ & $16.80 \pm 1.11^{*}$ & Independent \\
\hline AST (IU/I) & $211.20 \pm 33.10$ & $183.60 \pm 14.80$ & $262.60 \pm 51.50$ & $299.20 \pm 29.00 *$ & Independent \\
\hline ALT (IU/I) & $44.80 \pm 5.06$ & $85.40 \pm 17.30 *$ & $71.00 \pm 7.59 *$ & $75.00 \pm 27.27 *$ & Independent \\
\hline ALP (IU/I) & $206.60 \pm 13.95$ & $630.80 \pm 31.78^{*}$ & $298 \pm 32.86^{*}$ & $753.80 \pm 31.65^{*}$ & Additive \\
\hline BT (mg/dl) & $0.90 \pm 0.14$ & $0.74 \pm 0.05 *$ & $0.91 \pm 0.19$ & $1 \pm 0.33$ & Independent \\
\hline $\mathrm{BD}(\mathrm{mg} / \mathrm{dl})$ & $0.25 \pm 0.09$ & $0.19 \pm 0.06$ & $0.22 \pm 0.03$ & $0.24 \pm 0.01$ & Independent \\
\hline CPK (IU/I) & $1258 \pm 76.22$ & $1292 \pm 40.73$ & $1690 \pm 65.70^{*}$ & $2960 \pm 61.51 *$ & Additive \\
\hline LDH (IU/I) & $2735.80 \pm 88.32$ & $1810 \pm 34.67^{*}$ & $4076 \pm 81.10^{*}$ & $7862 \pm 65.14^{*}$ & Additive \\
\hline
\end{tabular}

* Mean difference of variable between control and case group is statistically significant. WBC, White blood cell; RBC, Red blood cell; HB, Hemoglobin; HCT, Hematocrit; MCV, Mean corpuscular volume; PLT, Platelet count; RDW, Red cell distribution width; AST, Aspartate aminotransferase; ALT, Alanine aminotransferase; ALP, Alkaline phosphatase; BT, Bilirubin total; BD, Bilirubin direct; CPK, Creatinine phosphokinase; LDH, Lactate dehydrogenase. 
Table 6. Hemato-biochemical responses to interaction of trichloroethylene (concentration 250 ppm) and heat stress $\left(\right.$ WBGT $=33 \pm 1^{\circ} \mathrm{C}$ )

\begin{tabular}{|c|c|c|c|c|c|}
\hline \multirow{2}{*}{$\begin{array}{l}\text { Hemato-Biochemical } \\
\text { Parameters }\end{array}$} & \multirow{2}{*}{$\begin{array}{c}\text { Control group }(\mathrm{N}=5) \\
0 \mathrm{ppm} / 23 \pm 1^{\circ} \mathrm{C}\end{array}$} & \multicolumn{4}{|c|}{ Exposed group $(N=5)$} \\
\hline & & $250 \mathrm{ppm}$ & $33 \pm 1^{\circ} \mathrm{C}$ & $250 \mathrm{ppm} / 33 \pm 1^{\circ} \mathrm{C}$ & Interaction \\
\hline WBC $\left(10^{3} / \mu \mathrm{l}\right)$ & $8.94 \pm 1.29$ & $13.10 \pm 1.11^{*}$ & $5.98 \pm 1.63^{*}$ & $4.98 \pm 1.08 *$ & Subtractive \\
\hline $\mathrm{RBC}\left(10^{6} / \mu \mathrm{l}\right)$ & $8.99 \pm 0.20$ & $8.29 \pm 0.38^{*}$ & $9.04 \pm 0.48$ & $8.28 \pm 0.48^{*}$ & Subtractive \\
\hline $\mathrm{HB}(\mathrm{g} / \mathrm{dl})$ & $16.04 \pm 0.40$ & $15.38 \pm 0.46^{*}$ & $17.0 \pm 0.49 *$ & $15.28 \pm 0.68^{*}$ & Subtractive \\
\hline HCT (\%) & $46.92 \pm 1.03$ & $43.76 \pm 1.73^{*}$ & $51.66 \pm 1.15^{*}$ & $45.36 \pm 1.50$ & Subtractive \\
\hline $\operatorname{MCV}(\mathrm{fl})$ & $52.20 \pm 1.09$ & $52.80 \pm 0.83$ & $57 \pm 2 *$ & $54.80 \pm 1.92 *$ & Subtractive \\
\hline $\operatorname{PLT}\left(10^{3} / \mu \mathrm{l}\right)$ & $727.20 \pm 45.10$ & $596.60 \pm 49.90 *$ & $669.60 \pm 46.20$ & $765.20 \pm 41.90$ & Independent \\
\hline RDW (\%) & $14.72 \pm 0.45$ & $14.66 \pm 0.76$ & $14.86 \pm 1.04$ & $16.78 \pm 1.92 *$ & Independent \\
\hline AST (IU/I) & $211.20 \pm 33.10$ & $183.60 \pm 14.80$ & $326.20 \pm 69.90^{*}$ & $233.40 \pm 43.00$ & Subtractive \\
\hline ALT (IU/I) & $44.80 \pm 5.06$ & $85.40 \pm 17.30^{*}$ & $77.20 \pm 8.09 *$ & $56.20 \pm 15.73$ & Subtractive \\
\hline ALP (IU/I) & $206.60 \pm 13.95$ & $630.80 \pm 31.78^{*}$ & $321.80 \pm 18.58^{*}$ & $662.60 \pm 31.72^{*}$ & Independent \\
\hline BT (mg/dl) & $0.90 \pm 0.14$ & $0.74 \pm 0.05^{*}$ & $1.01 \pm 0.22$ & $0.80 \pm 0.13$ & Subtractive \\
\hline $\mathrm{BD}(\mathrm{mg} / \mathrm{dl})$ & $0.25 \pm 0.09$ & $0.19 \pm 0.06$ & $0.28 \pm 0.10$ & $0.21 \pm 0.09$ & Subtractive \\
\hline CPK (IU/I) & $1258 \pm 76.22$ & $1292 \pm 40.73$ & $3300 \pm 80.82 *$ & $3376 \pm 59.56^{*}$ & Independent \\
\hline LDH (IU/I) & $2735.80 \pm 88.32$ & $1810 \pm 34.67^{*}$ & $3752 \pm 82.89 *$ & $6067.20 \pm 78.66^{*}$ & Additive \\
\hline
\end{tabular}

* Mean difference of variable between control and case group is statistically significant. WBC, White blood cell; RBC, Red blood cell; HB, Hemoglobin; HCT, Hematocrit; MCV, Mean corpuscular volume; PLT, Platelet count; RDW, Red cell distribution width; AST, Aspartate aminotransferase; ALT, Alanine aminotransferase; ALP, Alkaline phosphatase; BT, Bilirubin total; BD, Bilirubin direct; CPK, Creatinine phosphokinase; LDH, Lactate dehydrogenase.

\section{Results}

The observations showed that the 8-hour exposure to extreme heat stress resulted in pronounced signs such as high body temperature, rapid and shallow breathing and reduction in body weight. The data resulting from hemato-biochemical responses of studied rats to co-exposure to trichloroethylene $100 \mathrm{ppm}$ and WBGT $29 \pm 1^{\circ} \mathrm{C}$ was presented in Table 3. Mean blood WBC, PLT, ALT, ALP and CPK increased significantly in all the groups exposed to TCE $100 \mathrm{ppm}$ as compared to the control group $(\mathrm{P}<0.01)$, but there was a significant decrease for parameters RBC, HB and HCT $(P<0.01)$. Heat exposure (WBGT $29 \pm 1^{\circ} \mathrm{C}$ ) significantly resulted in a decrease in the levels of WBC, RBC, HB and HCT; although the raised levels of ALT, ALP, CPK and LDH were observed among rats exposed to the heat stress compared to the control group $(P<0.01)$. The values of MCV, ALT, ALP, CPK and LDH significantly increased during the simultaneous exposure of rats to permissible heat stress $\left(29 \pm 1^{\circ} \mathrm{C}\right)$ and trichloroethylene $100 \mathrm{ppm}$. Our results demonstrate an additive effect of these stressors in rats on value of CPK and ALP. Our results point to a subtractive or divisive effect of co-exposure of heat stress and trichloroethylene on WBC, RBC, PLT and LDH values. Moreover, the interaction of heat stress and trichloroethylene exposure for 10 consecutive days resulted in an independent effect in case of other hemato-biochemical parameters.

Table 4 shows the comparison result of the mean values of hemato-biochemical parameters between exposed and control groups after heat exposure to $\mathrm{WBGT} 33 \pm 1^{\circ} \mathrm{C}$. The extreme heat stress significantly caused an increase in blood HB, HCT, MCV, AST, ALT, ALP, CPK and LDH of the exposed group compared to control group $(P<0.001)$. Statistical analysis by independent sample $t$-test indicated the significant difference between WBC levels in the control group $\left(8.94 \pm 1.2910^{3} / \mu \mathrm{l}\right)$ with those values $(5.98 \pm 1.63$ $\left.10^{3} / \mu \mathrm{l}\right)$ in rats exposed to extreme heat stress $(\mathrm{P}<0.01)$. The rats exposed concomitantly to heat stress (WBGT $=33 \pm 1^{\circ} \mathrm{C}$ ) and trichloroethylene (concentration $100 \mathrm{ppm}$ ) had a significantly increase in levels of biochemical parameters including ALT, ALP, CPK and LDH compared to those values in control group $(P<0.001)$. The current study found that co-exposure to extreme heat stress and TCE caused the lower levels of hematological parameters such as WBC, RBC, HB, HCT and PLT in the exposed group in comparison with the rat with comfort heat condition of WBGT $23 \pm 1^{\circ} \mathrm{C}$ and no exposure to TCE $(P<0.01)$. These results suggest that the joint effects of co-exposure of the trichloroethylene and heat stress on ALP and LDH can be an additive interaction.

Another interrelation of simultaneous exposure to comfort and permissible heat stress and high concentrations of trichloroethylene $(250 \mathrm{ppm})$ is presented Table 5 . Rats exposed to 250 ppm TCE showed a significant decrease in levels of RBC, HB, HCT, PLT, BT and LDH and a significant increase in levels of WBC, ALT and ALP $(P<0.001)$. The simultaneous exposure to $250 \mathrm{ppm}$ concentration of TCE and WBGT $29 \pm 1^{\circ} \mathrm{C}$ induced a significant decrease in mean levels of WBC, RBC and PLT and also produced a statistically significant increase in mean levels of hematobiochemical such as MCV, RDW, AST, ALT, ALP, CPK and LDH $(\mathrm{P}<0.001)$

As can be seen in Table 6, the co-exposure to trichloroethylene (concentration $250 \mathrm{ppm}$ ) and heat stress (WBGT $=29 \pm 1^{\circ} \mathrm{C}$ ) lead to the additive interaction for levels of ALP, CPK and LDH, respectively.

Assessing the hemato-biochemical responses to interaction of high concentration trichloroethylene $(250 \mathrm{ppm})$ and extreme heat stress (WBGT $\left.=33 \pm 1^{\circ} \mathrm{C}\right)($ Table 6$)$ was revealed that there is the additive interaction for $\mathrm{LDH}$. The values of $\mathrm{WBC}, \mathrm{RBC}$ and $\mathrm{HB}$ significantly decreased after co-exposure $250 \mathrm{ppm}$ TCE and extreme heat stress; although, this exposure condition lead to statistically significant increase in mean levels of MCV, RDW, ALP, CPK and LDH.

\section{Discussion}

To the best of our knowledge, the present study was the first one to report the effect of in vivo co-exposure to trichloroethylene and heat stress on hemato-biochemical parameters in adult male Sprague-Dawley rats. In the study, WBC levels were significantly lower in the rats exposed to heat stress. Also, a negative relationship was found between the WBGT index and WBC value $(R=-0.52, P<0.05)$. These results are consistent with the study by Norloei et al. 2017, who reported that heat stress is able to decrease the number of $\mathrm{WBC}^{6}$. Also, Ondruska et al. 2011, noted that exposure to elevated levels of ambient temperature $\left(36 \pm 3{ }^{\circ} \mathrm{C}\right)$ decreased the number of WBCs of New Zealand white females growing rabbits [15]. Lowered WBC counts in humans and rats may imply lowered stem cell proliferation rates in the bone marrow. It 
tempted us to formulate a hypothesis that lowered cellular proliferation rates may be a common physiological characteristic in both rats and humans after increase in temperature [16].

Animals exposed to 100 and 250 ppm TCE had statistically significant increases in WBC levels compared to the controls. WBCs are the cells of the immune system that are involved in protecting the body against both infectious disease and foreign invaders. It may indicate that rats exposed to trichloroethylene levels enhance susceptibility to infection and that the immune system is working to destroy it. These findings are consistent with the data reported by Liu. 2009, who noted that the WBC levels were more than normal range in patients for whom trichloroethylene is used as the detergent to clean metal surface [17].

Hemato-biochemical analysis of blood indicated co-exposure to heat stress and TCE caused statistically significant decrease in total white blood cell. Based on these results, the joint effects of co-exposure of the trichloroethylene and heat stress on WBC levels is a subtractive interaction. Some studies have reported that exposure to high ambient temperature modifies various components of immune function such as $\mathrm{T}$ cell counts and lymphocyte a form of small leucocyte (white blood cell) proliferation [18]. Animal studies also suggest that at relatively high doses, and in one specific mouse model of systemic autoimmunity, exposure to trichloroethylene can induce an autoimmune syndrome which destroy WBCs or bone marrow cells [19]. This condition, also known as leukopenia, can have important effects on toxicological decision making, since WBC is a valuable indicator of immunocompetence, infection, and inflammation and can places animals and individuals at increased risk of infection. The low WBC counts as a result of such interactions may be due to immune system problems which destroy bone marrow cells. Consistent evidence existed to suggest that dichloroacetic acid (DCA) as metabolite of trichloroethylene could cause DNA damage (DNA unwinding) in studies in vivo in bone marrow and blood leukocytes in animals. Thus, heat stress increases sensitivity of WBCs to trichloroethylene and the simultaneous effects of exposure provide the circumstances for the occurrence of a variety of diseases [19].

Similar to WBC, we did observe heat exposure (WBGT $29 \pm 1^{\circ} \mathrm{C}$ ) significantly resulted in a decrease in the RBC counts and $\mathrm{HB}$ and HCT levels. According to a study by Seley (1960), heat stress in mammals may decreased the level of adrenocorticotropic hormone (ACTH) in the blood, which might then result in decreases in RBC counts and HB concentration [20].

The extreme heat stress (WBGT $33 \pm 1^{\circ} \mathrm{C}$ ) significantly caused an increase in blood HB and HCT of the exposed group compared to control group. This increase of HB and HCT levels can be due to the nutrient availability for $\mathrm{HB}$ synthesis because of consuming more food by rats or decreasing voluntary intake under sub-acute exposure to heat [21].

The present study also evaluated hematotoxicity potential of trichloroethylene on RBC, HB and HCT. Mean blood of those parameters decreased significantly in all the groups exposed to trichloroethylene as compared to the control group. The mechanism of these changes are not presently known. Mild macrocytic anemia has been observed in some workers occupationally exposed to trichloroethylene which may be a reason for the effect of this solvent on the bone marrow and cause disorder [22].
The interaction of trichloroethylene and heat stress on RBC, $\mathrm{HB}$ and HCT was mostly subtractive. The mechanism of these changes are not presently known. Unfortunately, there were no available satisfy data from the literature concluded clinical condition of the effects of co-exposure of heat stress and trichloroethylene in the RBC count and HB and HCT levels, but a subtractive effect can be a dangerous situation for these parameters.

Based on findings, the interaction of trichloroethylene (100 ppm) and heat stress on PLT levels was subtractive or divisive (antagonism) scale, however there was an independent interaction for 250 ppm groups. Very few studies have addressed the effects of simultaneous occupational exposure to heat stress and trichloroethylene on the PLT levels. There are no reports from such studies conducted on laboratory animals. PLTs stop bleeding by clumping and forming plugs in blood vessel injuries. Thrombocytopenia (a condition in which body have a low blood platelet count) often occurs as a result of a separate disorder, such as anemia, bone marrow disorders or an immune system problem. Zhang et al. (2012) observed that serum levels of both IgG and IgM were significantly decreased in workers exposed to trichloroethylene levels below $12 \mathrm{ppm}$, the median exposure level [23]. These results provide further evidence that trichloroethylene is immunotoxic at relatively low exposure levels. Also, evidencebased results show that heat stress creates a greater threat to immune function in comparison with thermo-neutral conditions [24].

Observed values of enzymes AST, ALT, and ALP were higher in rats exposed to heat stress compared to control group. Results showed that the sub-acute heat exposure can increase the levels of liver enzymes AST, ALT, and ALP which are consistent with much of the prior research indicated that the AST and ALP values for Beetal and Toggenburg goats between hot and cold seasons are considerably different [5]. Our results are consistent with the hypothesis that liver function is reduced at warmer environmental temperatures. Evidence from pharmacology science has demonstrated that toxicity increases with elevated temperatures [25]. Our data suggest that even sub-acute exposures to heat stress could significantly impair liver function and potentially the detoxification capacity of the male Sprague-Dawley rats. In acute hepatocellular injury, serum AST levels usually rise immediately, reaching a higher level than ALT initially, due to the higher activity of AST in hepatocytes and its release with liver injury. Within 24 to 48 hours, particularly if ongoing damage occurs, ALT will become higher than AST, because of its longer plasma half-life. In chronic hepatocellular injury, ALT is more commonly elevated than AST [26].

After inhalation exposure to the trichloroethylene, only ALT, ALP and CPK showed an increased value among the studied biochemical parameters. These findings are in agreement with Kumar et al. (2001), who showed a significant increase in all tested serum liver enzymes (ALP, GGTP and ALT) comparing to control group after 1 and 3 days' post trichloroethylene injection [27].

Our results demonstrate an additive interaction between exposure to trichloroethylene and heat stress for ALP enzyme in rats. Rats exposed to trichloroethylene and heat stress have a higher risk of increasing ALP level than those only exposed to one stressor (either trichloroethylene or heat stress alone). As previously mentioned, the co-exposure to trichloroethylene and heat stress lead to the subtractive or independent interaction for 
levels of AST and ALT, but there was an additive effect for ALP enzyme. Therefore, this interaction can't be due to the effect of simultaneous exposure on the liver.

Based on present study and other researches, the exposure to heat stress caused to increase the level of CPK enzymes [28]. These findings are in agreement with those obtained by Hubbard et al. 1979, indicating a significant increase in rat's blood CPK during 24 and $96 \mathrm{~h}$ exposure to heat [29]. This may be because the prolonged heat exposure affected the muscles, causing muscle infarction as well as its fatigue.

Serum level of CPK enzymes increased significantly in all the groups exposed to TCE $100 \mathrm{ppm}$ as compared to the control group. It was also observed the values of CPK increased during the exposure of rats to trichloroethylene $250 \mathrm{ppm}$, although it did not reach a level of statistical significance. It has been considered that the increase of CPK activity has some relations with the diseases of voluntary muscle and membrane permeability in those muscles [30].

Interestingly, except for extreme heat stress $\left(\mathrm{WBGT} \geq 33^{\circ} \mathrm{C}\right.$ ), all other combinations of concentrations of trichloroethylene $(\geq 100$ PPM) and heat stress (WBGT $=29 \pm 1^{\circ} \mathrm{C}$ ) after $8 \mathrm{~h}$ exposure indicating a very severe additive effect for value of CPK in rats (see Table 3\&5). Clinically, high levels of CPK in the blood may be an indication of damage to CPK-rich tissue such as in rhabdomyolysis (severe muscle breakdown), muscular dystrophy, autoimmune myositides, and kidney injury which as mentioned previously all are related to the destructive effects of trichloroethylene or heat stress [31].

But with increasing heat stress $\left(\mathrm{WBGT} \geq 33^{\circ} \mathrm{C}\right.$ ), their additive effects decreased for those value (see Table 4\&6). These results suggest that concentrations of trichloroethylene act additively to harmful effects of heat stress for value of CPK up to certain level limit. After the permissible limit, these may work antagonistically or independently with trichloroethylene. CPK catalyzes the conversion of creatine and utilizes adenosine triphosphate (ATP) to create phosphocreatine $(\mathrm{PCr})$ and adenosine diphosphate (ADP). PCr serves as an energy reservoir for the rapid buffering and regeneration of ATP in situ, as well as for intracellular energy transport by the $\mathrm{PCr}$ shuttle or circuit [32]. Thus CPK is an important enzyme in such tissues and the antagonistic effects of trichloroethylene and extreme heat stress $\left(\mathrm{WBGT} \geq 33^{\circ} \mathrm{C}\right.$ ) may reduce the body's energy resources.

The present experiment confirms evidence presented earlier in that high temperature caused increased LDH activities of broilers in the in vitro and in vivo systems [33]. LDH is an enzyme involved in energy production that is found in almost all of the body's cells, with the highest levels found in the cells of the heart, liver, muscles, and kidney and in blood cells. When illness or injury damages cells, LDH may be released into the bloodstream, causing the level of LDH in blood to rise [34]. Several studies have also demonstrated correlation between heart, liver [35], kidney and blood disorders with heat [36]. Thus, high levels of LDH indicate some form of tissue damage [6].

We found rats exposed to $250 \mathrm{ppm}$ TCE showed a significant decrease in levels of LDH. These findings are in agreement with Cummings et al. (2000), who reported trichloroethylene caused modest cytotoxicity in freshly isolated human proximal tubular (hPT) cells, as assessed by significant decreases in LDH activity after $1 \mathrm{hr}$ of exposure to $500 \mu \mathrm{M}$ trichloroethylene [36]. It should be noted that decrease in total LDH activity, rather than LDH release, was used as an index of cytotoxicity, because trichloroethylene was found to inhibit LDH activity in hPT cells.

The most striking result to emerge from the data is that combined exposure to trichloroethylene and heat stress have induced additive effect on LDH enzyme. But, comfort environmental temperatures, up to $\mathrm{WBGT}=29^{\circ} \mathrm{C}$, and lower solvent concentrations caused antagonism effect in the serum LDH levels. Present research was the first to report those effects, but a number of studies have demonstrated the relationship between LDH enzyme levels and co exposure to ambient temperatures and inorganic compounds.

\section{Conclusion}

Our findings indicated that there were the subtractive (antagonism) and independent interactions for the hematological parameters and the additive, subtractive and independent interactions for biochemical parameters based on the exposure level to trichloroethylene and heat stress. However, the single effects of heat stress and TCE exposure on the hematobiochemical parameters could be completely different from the effects of simultaneous exposures to these stressors.

\section{Ethical approva}

Ethical approval for this study was obtained from School of Health Shiraz University of Medical Sciences (Project no. 1396-01-04-15122).

The procedures have been approved also by a national ethics committee, and the protocol conforms to the guidelines of CPCSEA (Committee for the Purpose of Control and Supervision of Experiments on Animals).

\section{Conflict of Interest}

The authors declare that there is no conflict of interest.

\section{Funding}

This study was part of a PhD dissertation and research project supported by Shiraz University of Medical Sciences (Grant no. 1396-01-0415122).

\section{Acknowledgement}

The authors would like to thank Larestan University of Medical Sciences and pathology laboratory of Dr. Modaressi for their invaluable assistance.

\section{References}

1. Ramdhan DH, Kamijima M, Yamada N, Ito $Y$, Yanagiba $Y$, Nakamura $D$, Nakajima T, et al. Molecular mechanism of trichloroethylene-induced hepatotoxicity mediated by CYP2E1. Toxicol Appl Pharmacol 2008, 231(3): 300-307. https://doi.org/10.1016/j.taap.2008.04.020.

2. Ramdhan $D H$, Kamijima $M$, Wang $D$, Ito $Y$, Naito $H$, Yanagiba $Y$, Nakajim $T$, et al. Differential response to trichloroethylene-induced hepatosteatosis in wild-type and PPAR $\alpha$-humanized mice. Environ Health Perspect 2010; 118(11): 1557-1563. https://doi.org/10.1289/ehp.1001928.

3. Rathwa SD, Vasava AA, Pathan MM, Madhira SP, Patel YG, Pande AM Effect of season on physiological, biochemical, hormonal, and oxidative stress parameters of indigenous sheep. Vet World 2017; 10(6): 650-654. https://doi.org/10.14202/vetworld.2017.650-654.

4. Srikandakumar A, JohnsonE HE, Mahgoub O (2003) Effect of heat stress on respiratory rate, rectal temperature and blood chemistry in 
Omani and Australian Merino sheep. Small Rumin Res 2003; 49(2): 193-198. https://doi.org/10.1016/S0921-4488(03)00097-X.

5. Gattani A, Pathak A, Kumar A, Mishra V, Bhatia JS. Influence of season and sex on hemato-biochemical traits in adult turkeys under arid tropical environment. Vet World 2016; 9(5): 530-534. https://doi.org/10.14202/vetworld.2016.530-534.

6. Norloei S, Jafari MJ, Omidi L, Khodakarim S, Bashash D, Abdollahi MB, et al. The effects of heat stress on a number of hematological parameters and levels of thyroid hormones in foundry workers. Int J Occup Saf Ergon 2017; 23(4): 481-490. https://doi.org/10.1080/10803548.2016.1246122.

7. LeonL R Thermoregulatory responses to environmental toxicants: The interaction of heat stress and toxicant exposure. Toxicol Appl Pharmacol 2008; 233(1): 146-161. https://doi.org/10.1016/i.taap.2008.01.012.

8. Gordon CJ, Johnstone AF, Aydin C. Thermal stress and toxicity. Compr Physiol 2014; 4(3): 995-1016. https://doi.org/10.1002/cphy.c130046.

9. ISO. Hot Environments - Estimation of the heat stress on working man, based on the WBGT index (Web Bulb Globe Temperature). Geneva: International Standards Organization: ISO. ISO 7243. 1989; 9 p. https://www.iso.org/standard/13895.html.

10. Namiesīnik J. Generation of standard gaseous mixtures. J Chromatogr A 1984; 300: 79-108. https://doi.org/10.1016/S0021-9673(01)87581-6.

11. Koziel JA, Martos PA, Pawliszyn J. System for the generation of standard gas mixtures of volatile and semi-volatile organic compounds for calibrations of solid-phase microextraction and other sampling devices. J Chromatogr A 2004; 1025(1): 3-9. https://doi.org/10.1016/j.chroma.2003.10.079.

12. Occupational Safety and Health Administration. 1910.1000 - Air contaminants. Occupational Safety and Health Standards. Permissible Exposure Limits (PELS), from 29 CFR 1910.1000. Table Z-2. 2006. https://www.osha.gov/laws-

regs/regulations/standardnumber/1910/1910.1000TABLEZ2.

13. Ramsey JD, Burford CL, Beshir MY, Jensen RC. Effects of workplace heat conditions on safe work behavior. J Saf Res. 1983; 14(3): 105-114. https://psycnet.apa.org/doi/10.1016/0022-4375(83)90021-X.

14. Winder C, Stacey NH, Eds. Occupational toxicology. 2nd ed. New York: CRC press. 2004; 624 p. https://www.worldcat.org/title/occupationaltoxicology/oclc/52251543.

15. Ondruska L, Rafay J, Okab AB, Ayoub MA, Al-Haidary AA, Samara EM, et al. Influence of elevated ambient temperature upon some physiological measurements of New zealand White rabbits. Vet Med 2011; 56: 180-186. https://doi.org/10.17221/3150-VETMED.

16. Koizumi A, Roy NS, Tsukada M, Wada Y. Increase in housing temperature can alleviate decreases in white blood cell counts after energy restriction in C57BL/6 female mice. Mech Ageing Dev 1983; 71(1-2): 97-102. https://doi.org/10.1016/0047-6374(93)90038-s.

17. Liu J. Clinical analysis of seven cases of trichloroethylene medicamentose-like dermatitis. Ind Health 2009; 47(6): 685-688. https://doi.org/10.2486/indhealth.47.685.

18. Shephard RJ. Immune changes induced by exercise in an adverse environment. Can J Physiol Pharmaco 1998; 76(5): 539-546. https://doi.org/10.1139/cjpp-76-5-539.

19. Gilbert KM, Przybyla B, Pumford NR, Han T, Fuscoe J, Schnackenberg LK, et al. Delineating liver events in trichloroethylene-induced autoimmune hepatitis. Chem Res Toxicol 2009; 22(4): 626-632. https://doi.org/10.1021/tx800409r.

20. Selye $H$. The concept of stress in experimental physiology. In: Tanner JM, Ed. Stress and Psychiatric disorder. 1st ed. Oxford: Blackwell. 1960: 67-75.

21. Rana MS, Hashem MA, Sakib MN, Kumar A (2014) Effect of heat stress on blood parameters in indigenous sheep. J Bangladesh Agril Univ 2014; 12(1): 91-94. http://dx.doi.org/10.22004/ag.econ.209902.
22. Qasim FK, Ahmed AH. Effects of welding fume particles on heamatological parameters in male Albino rats. Zanco J Med Sci 2013; 17(2): 422-428. https://www.iasj.net/iasj/article/158805.

23. Zhang L, Bassig BA, Mora JL, Vermeulen R, Ge Y, Curry JD, et al. Alterations in serum immunoglobulin levels in workers occupationally exposed to trichloroethylene. Carcinogenesis 2013; 34(4): 799-802. https://doi.org/10.1093/carcin/bgs403.

24. Walsh NP, Gleeson M, Pyne DB, Nieman DC, Dhabhar FS, Shephard RJ, et al. Position statement part two: maintaining immune health. Exerc Immunol Rev 2011; 17: 64-103. https://pubmed.ncbi.nlm.nih.gov/21446353.

25. Kurnath $P$, Dearing MD. Warmer ambient temperatures depress liver function in a mammalian herbivore. Biol Lett 2013; 9(5): 20130562. https://doi.org/10.1098/rsbl.2013.0562.

26. Kim WR, Flamm SL, Di Bisceglie AM, Bodenheimer HC; Public Policy Committee of the American Association for the Study of Liver Disease. Serum activity of alanine aminotransferase (ALT) as an indicator of health and disease. Hepatology 2008; 47(4): 1363-1370. https://doi.org/10.1002/hep.22109.

27. Kumar P, Prasad AK, Maji BK, Mani U, Dutta KK. Hepatoxic alterations induced by inhalation of trichlorethylene (TCE) in rats. Biomed Environ Sci 2001; 14(4): 325-332. https://pubmed.ncbi.nlm.nih.gov/11862613.

28. Ahamed SM, Ahmed OA, Eldin ES, Elmoubarak AO, Elfaki I. Modawe GA. Effect of Direct Sun Heat Exposure on Creatinine \& Creatine Kinase Level. Br J Med Health Res 2015; 2: 10-16.

29. Hubbard RW, Criss RE, Elliott LP, Kelly C, Matthew WT, Bowers WD, et al. Diagnostic significance of selected serum enzymes in a rat heatstroke model. J Appl Physiol Respir Environ Exerc Physiol 1979; 46(2): 334-339.. https://doi.org/10.1152/jappl.1979.46.2.334.

30. Sudo A, Hasegawa $H$, Sato $M$, Honma $T$, Miyagawa $M$, Okonogi K. Influence of trichloroethylene in each process of ageing of rats. Ind Health 1979; 17: 233-238.

31. Moghadam-Kia S, Oddis CV, Aggarwal R. Approach to asymptomatic creatine kinase elevation. Cleve Clin J Med 2016; 83(1): 37-42. https://doi.org/10.3949/ccjm.83a.14120.

32. Wallimann T, Wyss M, Brdiczka D, Nicolay K, Eppenberger HM. Intracellular compartmentation, structure and function of creatine kinase isoenzymes in tissues with high and fluctuating energy demands: the'phosphocreatine circuit'for cellular energy homeostasis. Biochem J 1992; 281(Pt 1)(Pt 1): 21-40. https://doi.org/10.1042/bj2810021.

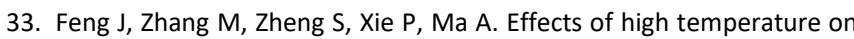
multiple parameters of broilers in vitro and in vivo. Poult Sci 2008 87(10): 2133-2139. https://doi.org/10.3382/ps.2007-00358.

34. Ding J, Karp J E, Emadi A. Elevated lactate dehydrogenase (LDH) can be a marker of immune suppression in cancer: Interplay between hematologic and solid neoplastic clones and their microenvironments. Cancer Biomark 2017; 19(4): 353-363. https://doi.org/10.3233/cbm160336.

35. Bai L, Li Q, Wang J, Lavigne E, Gasparrini A, Copes R, et al. Increased coronary heart disease and stroke hospitalisations from ambient temperatures in Ontario. Heart 2018; 104(8): 673-679. https://doi.org/10.1136/heartjnl-2017-311821.

36. Cummings BS, Lasker JM, Lash LH. Expression of glutathionedependent enzymes and cytochrome P450s in freshly isolated and primary cultures of proximal tubular cells from human kidney. J Pharmacol Exp Ther 2000; 293(2): 677-685. https://pubmed.ncbi.nlm.nih.gov/10773044/.

\section{Authors:}

Zahra Zamanian - PhD, Associate Professor, Department of Occupational Health Engineering, School of Health, Shiraz University of Medical Sciences, Shiraz, Iran. https://orcid.org/0000-0003-2462-2456. 
Saeed Yousefinejad - PhD, Associate Professor, Department of Occupational Health Engineering, School of Health, Shiraz University of Medical Sciences, Shiraz, Iran. https://orcid.org/0000-0001-5940-1229.

Somayeh Farhang Dehghan - PhD, Assistant Professor, Environmental and Occupational Hazards Control Research Center, School of Public Health and Safety, Shahid Beheshti University of Medical Sciences, Tehran, Iran. https://orcid.org/0000-0002-6607-6396.

Abdolrasoul Rahmani - PhD, Assistant Professor, Department of Occupational Health and Safety, School of Health, Larestan University of Medical Sciences, Larestan, Iran. https://orcid.org/0000-0002-9615-4391. 